\title{
A Solvent-Free, One-Step, One-Pot Gewald Reaction for Alkyl-aryl Ketones via Mechanochemistry
}

\author{
William C. Shearouse, Maxwell Z. Shumba and James Mack* \\ University of Cincinnati, Cincinnati, OH 45221-0172, USA; \\ E-Mails: willshearouse@me.com (W.C.S.); mshumba@threebond.com (M.Z.S.) \\ * Author to whom correspondence should be addressed; E-Mail: james.mack@uc.edu; \\ Tel.:+1-513-556-9249; Fax: +1-513-556-9239.
}

Received: 16 November 2013; in revised form: 25 February 2014 / Accepted: 18 March 2014 /

Published: 8 April 2014

\begin{abstract}
Herein, we report on the solvent-free synthesis of 2-aminothiophenes via the Gewald reaction. Utilizing high speed ball milling conditions, we discovered the Gewald reaction can be catalytic in base, and conducted under aerobic conditions. Using thermal heat in tandem with the mixer/mill significantly increases the rate of reaction.
\end{abstract}

Keywords: Gewald; solvent-free; ball milling; green chemistry; multicomponent reaction

\section{Introduction}

Polysubstituted 2-aminothiophenes have shown to be versatile synthetic building blocks in the dye and other industries [1,2]. These useful compounds have also been significant with respect to their biological activity [3-5]. Due to their importance and versatility, the chemistry of 2-aminothiophenes has received much attention and several synthetic methods have been published [6-8]. Many of the methods reported involve difficult preparation of starting materials and multi-step synthesis. The most convenient method for preparing 2-aminothiophenes with a high degree of substitution is the Gewald reaction (Scheme 1) [9]. The Gewald method, involves the reaction of ketones, aldehydes or 1,3-dicarbonyl species with activated nitriles and elemental sulfur in the presence of an amine base. This method is an improvement over other existing routes for the synthesis of 2-aminothiophenes [10,11].

Although the Gewald reaction possesses very good synthetic utility, there are three different variations which tailor the reaction for specific substrates. Of the three variations the second version of 
the Gewald reaction, which consists of a one-pot procedure, is the most efficient and straightforward. However, literature reports indicate aryl ketones show limited reactivity.

Scheme 1. Three variations of the Gewald Reaction.

Variation 1<smiles></smiles>

Variation 2<smiles>[R]CC([R])=O</smiles>

Variation 3

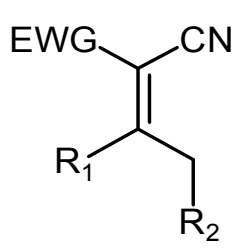

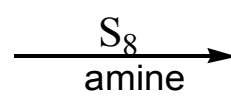<smiles>[R]c1sc(N)c(C#N)c1[R]</smiles>

Recently Tomyshev, Flinn and co-workers developed a two-step, one-pot method for conducting the Gewald reaction with aryl ketones in high yield. In this version, sulfur is added in 3 portions, with the first portion being added after $3 \mathrm{~h}$ and subsequent additions of sulfur are needed over a period of $8-12 \mathrm{~h}$ [12]. The overall reaction time in this procedure is $36-40 \mathrm{~h}$ with isolated yields of $25 \%-70 \%$ of various 4 -aryl-substituted 2-aminothiophene-3-carboxylates.

Many modifications to the Gewald reaction have been developed including the use of solid support [13-15], microwave irradiation [16,17], ionic liquids [18,19], and with heterogeneous catalyst [20].

Given the importance of this reaction in various industries, as well as in the building of combinatorial libraries, we wanted to develop a consistent one-step one-pot method for the Gewald reaction. We thought conducting this reaction via high speed ball milling (HSBM) would be less cumbersome and lead to a significant rate enhancement.

HSBM is an environmentally benign method by which reagents are placed inside a vessel along with a ball-bearing that is shaken at high speeds in the absence of solvent [21-23]. The high speed attained by the ball-bearing has enough force to make an amorphous mixture of the reagents which in turn facilitates a chemical reaction. This method has been studied in metal alloying and for the generation of inorganic salts but this methodology is relatively new to organic synthesis. 
One of our research goals is focused on increasing the rate of multi-component reactions (MCR's). We recently demonstrated an increase in rate of the Baylis-Hillman reaction via HSBM conditions [24]. The success we had with the ball milled Baylis-Hillman reaction, coupled with our desire to obtain the polyfunctionalized Gewald products in a one-step, one-pot process, stimulated our interest towards the use of HSBM for this reaction. Because aryl ketones are known to react sluggishly in the Gewald reaction, we decided to use aryl ketones in our study of this reaction under ball milling conditions.

\section{Experimental Section}

\subsection{General Procedure}

All NMR spectra were recorded on a Bruker Avance 400 spectrometer (Billerica, MA, USA). Deuterated NMR solvents were obtained from Cambridge Isotope Laboratories, Inc., Andover, MA, USA, and used without further purification. $p$-bromoacetophenone, $p$-chloroacetophenone, 3'-(N-Acetylamino)acetophenone, acetophenone, $p$-nitroacetophenone, were purchased from Acros Organics (New Jersey, NJ, USA) and used without further purification. $p$-cyanoacetophenone was purchased from Sigma-Aldrich (Milwaukee, WI, USA) and used without further purification. Ball milling was carried out in a $8000 \mathrm{M}$ SpexCertiprep Mixer/Mill (Metuchen NJ, USA). Ball bearings were purchased from Small Parts incorporated (Logansport, IN, USA). Custom made vials were made by the machine shop at the University of Cincinnati with metal rods purchased from ESPICorps Inc (Ashland, OR, USA).

\subsection{Typical Procedure for HSBM Preparation of 2-Aminothiophenes}

A $3 \mathrm{~mL}$ stainless steel HSBM vial was charged with $2 \mathrm{mmol}$ of acetophenone $(0.330 \mathrm{~g}, 2 \mathrm{mmol})$, sulfur $(0.064 \mathrm{~g}, 2 \mathrm{mmol})$, ethylcyanoacetate $(0.226 \mathrm{~g}, 2 \mathrm{mmol})$ and morpholine $(0.174 \mathrm{~g}, 2 \mathrm{mmol})$, together with a $1 / 8$ th inch stainless steel ball. The vial was sealed with a Teflon ${ }^{\circledR}$ gasket and fixed in a Spex $^{\circledR}$ (Metuchen, NJ, USA) $8000 \mathrm{M}$ mixer/mill and milled for $24 \mathrm{~h}$. The crude reaction mixture was quenched with water and extracted with methylene chloride. The organic layer was dried over anhydrous magnesium sulfate and the solvent was removed in vacuo. The resulting yellow mixture was purified by column chromatography using a 1:1 $\mathrm{CH}_{2} \mathrm{Cl}_{2}$-cyclohexane eluent to afford the 4-phenyl-2-aminothiophene-3-carboxylic acid ethyl ester in 32\% yield.

\subsection{Oven Preparation of 2-Aminothiophenes}

A $100 \mathrm{~mL}$ round bottom flask was charged with $2 \mathrm{mmol}$ of acetophenone $(0.330 \mathrm{~g}, 2 \mathrm{mmol})$, sulfur (0.064 g, $2 \mathrm{mmol})$, ethylcyanoacetate $(0.226 \mathrm{~g}, 2 \mathrm{mmol})$ and morpholine $(0.174 \mathrm{~g}, 2 \mathrm{mmol})$, and lightly swirled. The flask was left open to atmospheric conditions and placed in a $120^{\circ} \mathrm{C}$ oven for one hour.

The crude reaction mixture was quenched with water and extracted with methylene chloride. The organic layer was dried over anhydrous magnesium sulfate and the solvent was removed in vacuo. The resulting yellow mixture was purified by column chromatography using a 1:1 $\mathrm{CH}_{2} \mathrm{Cl}_{2}$-cyclohexane eluent to afford the 4-phenyl-2-aminothiophene-3-carboxylic acid ethyl ester in 43\% yield. 


\subsection{Heat Assisted HSBM Preparation of 2-Aminothiophenes}

A $3 \mathrm{~mL}$ stainless steel HSBM vial was charged with $2 \mathrm{mmol}$ of acetophenone $(0.330 \mathrm{~g}, 2 \mathrm{mmol})$, sulfur $(0.064 \mathrm{~g}, 2 \mathrm{mmol})$, ethylcyanoacetate $(0.226 \mathrm{~g}, 2 \mathrm{mmol})$ and morpholine $(0.174 \mathrm{~g}, 2 \mathrm{mmol})$, together with a $1 / 8$ th inch stainless steel ball. The vial was sealed with a Teflon ${ }^{\circledR}$ gasket and fitted to an aluminium heating sleeve fixed in a Spex ${ }^{\circledR}$ (Metuchen, NJ, USA) $8000 \mathrm{M}$ mixer mill modified to accompany a heat gun. The reaction was mixed vigorously for $0.5 \mathrm{~h}(30 \mathrm{~min})$ at a rate of 1080 oscillations per minute $(18 \mathrm{~Hz})$ while continuously being heated by the heat gun to a temperature of $130{ }^{\circ} \mathrm{C}$. The crude reaction mixture was quenched with water and extracted with methylene chloride. The organic layer was dried over anhydrous magnesium sulfate and the solvent was removed in vacuo. The resulting yellow mixture was purified by column chromatography using a 1:1 $\mathrm{CH}_{2} \mathrm{Cl}_{2}$-cyclohexane eluent to afford the 4-phenyl-2-aminothiophene-3-carboxylic acid ethyl ester in $53 \%$ yield.

\subsection{Oven Preparation of 2-Aminothiophenes Using a Catalytic Amount of Base}

A $100 \mathrm{~mL}$ round bottom flask was charged with $2 \mathrm{mmol}$ of acetophenone $(0.330 \mathrm{~g}, 2 \mathrm{mmol})$, sulfur (0.064 g, $2 \mathrm{mmol})$, ethylcyanoacetate $(0.226 \mathrm{~g}, 2 \mathrm{mmol})$ and morpholine $(0.174 \mathrm{~g}, 2 \mathrm{mmol})$, and lightly swirled. The flask was left open to atmospheric conditions and placed in a $120{ }^{\circ} \mathrm{C}$ oven for one hour. The crude reaction mixture was quenched with water and extracted with methylene chloride. The organic layer was dried over anhydrous magnesium sulfate and the solvent was removed in vacuo. The resulting yellow mixture was purified by column chromatography using a 1:1 $\mathrm{CH}_{2} \mathrm{Cl}_{2}$-cyclohexane eluent to afford the 4-phenyl-2-aminothiophene-3-carboxylic acid ethyl ester in 43\% yield.

\section{Results and Discussion}

In a typical fashion the ketone $(2 \mathrm{mmol})$, ethylcyanoacetate $(2 \mathrm{mmol})$, sulfur $(2 \mathrm{mmol})$ and morpholine $(2 \mathrm{mmol})$ were added to a custom made $1 / 2 " \times 2$ " screw-capped stainless steel vial and milled with a Spexcertiprep mixer/mill $8000 \mathrm{M}$ for $24 \mathrm{~h}$ with a 1/8" inch stainless steel ball-bearing (Scheme 2).

Scheme 2. Representative solvent-free Gewald reaction via high speed ball milling (HSBM).

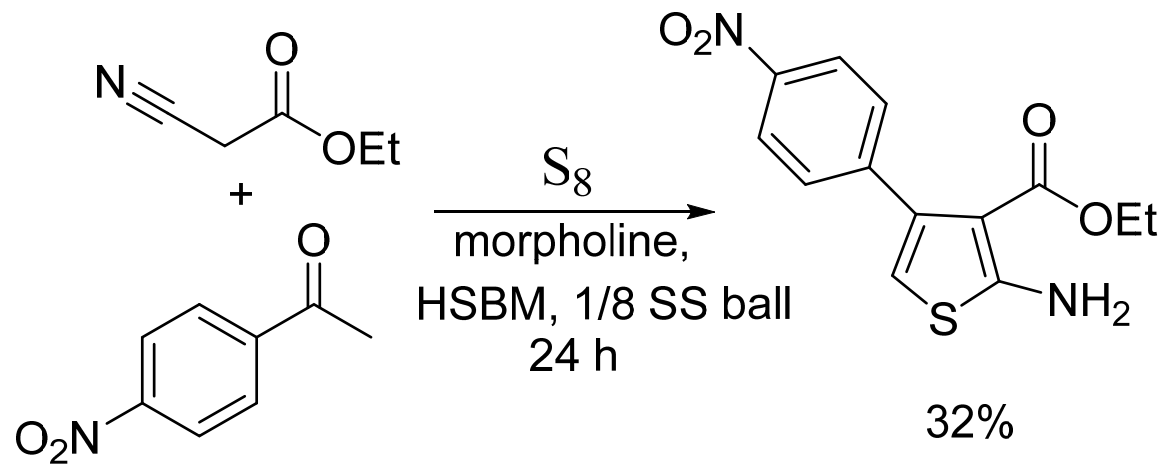

At the conclusion of the reaction, the crude product was washed with water and products were isolated by column chromatography. ${ }^{1} \mathrm{H}$ NMR, ${ }^{13} \mathrm{C}$ NMR, GC-MS were obtained on the products and compared to literature values. The results are summarized in Table 1. 
Using our initial conditions we observed moderate yields of 2-aminothiophenes with aryl ketones. Similar to solution based Gewald reactions aryl groups substituted with electron-donating groups react slower than those with electron withdrawing groups. In order to improve the yield and reaction rate, we investigated various aspects of this reaction under ball milling conditions.

Table 1. Reactions of $p$-substituted acetophenones with malonitrile, sulfur and morpholine by high speed ball milling ${ }^{\text {a }}$.

\begin{tabular}{|c|c|c|c|c|c|}
\hline $\begin{array}{l}\text { Starting } \\
\text { Ketone }\end{array}$ & Product & $\begin{array}{c}\text { HSBM, } \\
24 \mathrm{~h} \\
\end{array}$ & $\begin{array}{c}\text { Oven, } 120{ }^{\circ} \mathrm{C}, \\
1 \mathrm{~h} \mathrm{~h}\end{array}$ & $\begin{array}{c}\text { HSBM, } 0.5 \text { h, } \\
\text { heat gun }\end{array}$ & $\begin{array}{c}\text { Oven, } 120^{\circ} \mathrm{C}, \\
1 \text { h. cat. morpholine }\end{array}$ \\
\hline & & 41 & 29 & 14 & 19 \\
\hline & & 32 & 43 & 53 & 43 \\
\hline & & 30 & 27 & 25 & 19 \\
\hline & & 27 & 26 & 22 & 20 \\
\hline & & 27 & 31 & 32 & 36 \\
\hline & & 12 & 25 & 15 & 5 \\
\hline
\end{tabular}

${ }^{a}$ Typical reaction used $2 \mathrm{mmol}$ of ketone, $2 \mathrm{mmol}$ of ethylcyanoacetate and $2 \mathrm{mmol}$ sulfur and $2 \mathrm{mmol}$ morpholine . All yields are reported as isolated yields.

A recent report by Wang and results from our own lab suggest base reactivity is different under ball milling conditions than they are in solution [25]. In solution it was demonstrated that only morpholine gave high yields of thiophene product using the Gewald reaction. To that end, we examined the use of various bases to determine the effect it has on the reaction rate. Bases such as sodium bicarbonate, potassium carbonate, sodium hydroxide, triethylamine, pyridine, piperidine and morpholine were analyzed under HSBM reaction conditions. Various amine bases (triethylamine, pyridine, piperidine) produced yields similar to what is reported in Table 1, however we observed no product formation when sodium bicarbonate, potassium carbonate or sodium hydroxide was used as the base.

We next investigated the effect of reagent to vial ratio (i.e., the ratio of the amount of reagents that fill the volume of the vial) has on the rate and yield of our ball milled reaction. In our intial experiments we began using $1 \mathrm{mmol}$ of all of the reagants. When these reagents were placed into our vial it covered roughly $10 \%$ of the vial capacity. The extent that the reagents fill the vial has been postulated as an important factor to consider in ball milled reactions. Unlike reactions that are conducted in a stirred solution, homogeneity in HSBM reactions is not achieved instantaneously. If the reagent to vial ratio is low, then it would take a longer time before all the components could react together. If the reagents to 
vial ratio is too high then there is not enough voided space in the vial to be able to have the ball move throughout the reaction and provide the energy needed to cause the reaction to occur. We postulated that the reagent to vial ratio would be more essential for MCR's since these reactions rely on a series of bimolecular reactions before the final product is formed. Increasing the reagent to vial ratio would increase the reaction rate and give a higher yield of product. Using $p$-nitroacetophenone as the ketone ( 1 equivalent), ethylcyanoacetate ( 1 equivalent), sulfur ( 1 equivalent) and morpholine ( 1 equivalent) we conducted the ball milled Gewald reaction at ketone concentrations of $1 \mathrm{mmol}, 3 \mathrm{mmol}, 5 \mathrm{mmol}$, $7 \mathrm{mmol}$, and $9 \mathrm{mmol}$; this corresponds to approximately 10\%, 25\%, 50\%, 75\% and 95\% vial capacity. Each experiment was done in duplicate and the products isolated by chromatography. Surprisingly we discovered that irrespective of the reagent to vial ratio each reaction gave similar yields.

The highest impact energy in a ball milled reaction occurs when the ball impacts the wall of the vial at a $90^{\circ}$ angle [26]. Unfortunately this type of interaction only occurs for less than $1 \%$ of all impacts. If the energy needed to overcome the activation barrier of the Gewald reaction only occurs when the ball impacts the vial at a $90^{\circ}$ angle, then long reaction times would be needed as most of the ball impacts provide insufficient energy. To overcome this energy defiency we decided to heat the regents under solvent-free conditions in a conventional oven (Scheme 3). The reagents were added to a $100 \mathrm{~mL}$ round bottomed flask and heated at $120{ }^{\circ} \mathrm{C}$ for one hour. The products were isolated by column chromatography and the yields are reported in Table 1 . We observed that the yields of conducting the reaction in one hour in a conventional oven were comparable to ball milling for $24 \mathrm{~h}$. This suggests that most of the ball collisions did not provide enough energy to overcome the activation barrier for the Gewald reaction.

Scheme 3. Solvent-free Gewald reaction heated in a conventional oven.
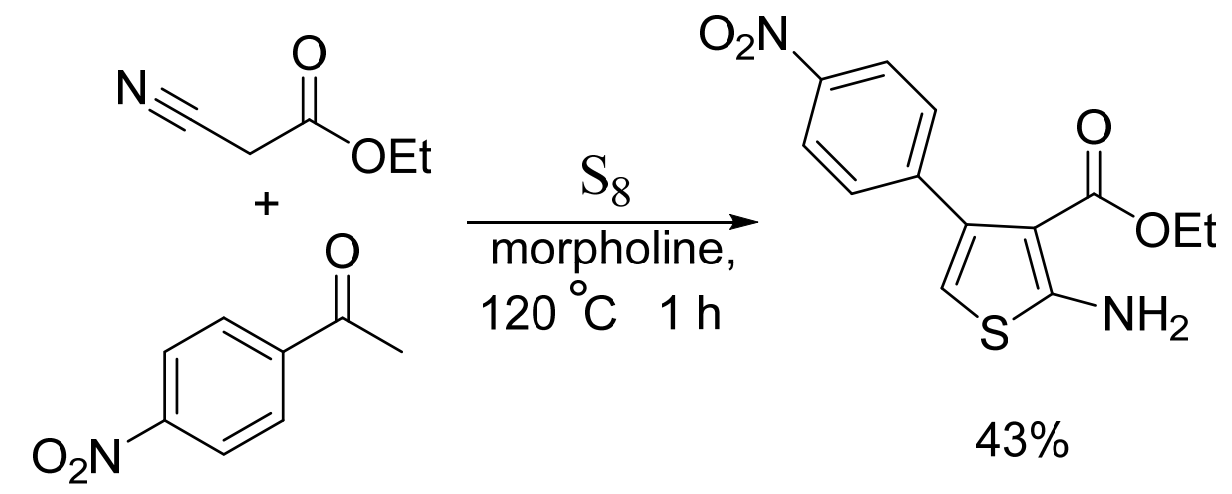

Although heating the reagents in a conventional oven led to formation of the thiophene product, the reaction occurred in moderate yield. Because the reaction in the conventional oven was not agitated, poor mixing could be responsible for the moderate yield. It would be reasonable to find a method that combines the heating of the oven with the mixing of the ball mill.

We modified our Spex $8000 \mathrm{M}$ mixer/mill to accommodate a heat gun that operated simultaneously upon milling. Upon conducting the reaction under our heated milling conditions for 30 min we observed similar yields to the milling alone and heating alone, but the rate of the reaction was significantly increased (Scheme 4). 
Scheme 4. Solvent-free heat assisted ball milling of the Gewald reaction.

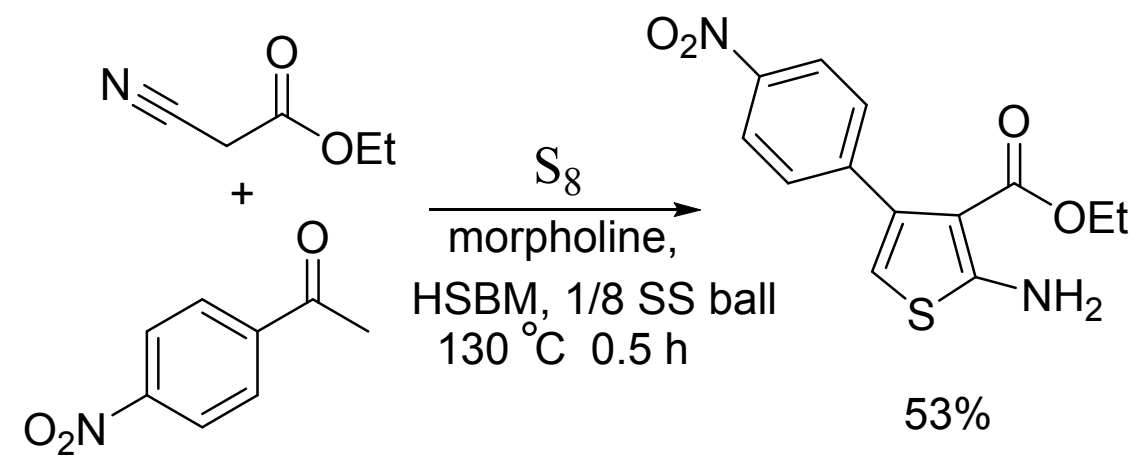

The mechanism of the Gewald reaction is thought to be the initial Knoevenagel condensation followed by attack of elemental sulfur, cyclization and protonation. Under solvent-free conditions the proton in the protonation step could come from the conjugate acid of morpholine suggesting the solvent-free reaction could be catalytic in base. Adding the reagents to a $100 \mathrm{~mL}$ round bottomed flask at $120{ }^{\circ} \mathrm{C}$ using $10 \%$ morpholine as catalyst provided product yields similar to observations in our other experiments demonstrating the catalytic nature of the reaction under solvent-free conditions (Scheme 5).

Scheme 5. Solvent-free Gewald reaction using catalytic base.

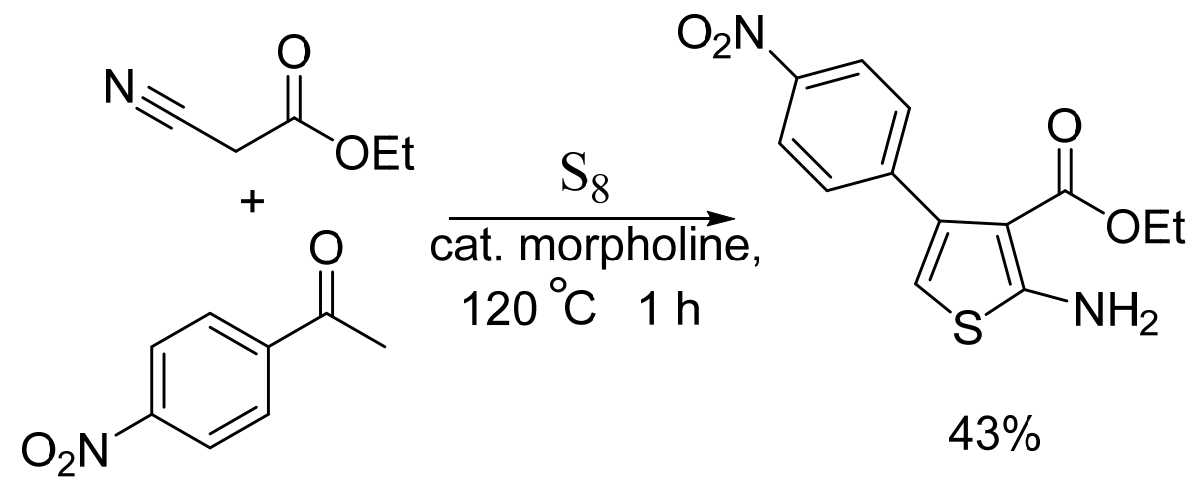

\section{Conclusions}

In conclusion, using HSBM we were able to develop a one-step one-pot method for conducting the Gewald synthesis with aryl-alkyl ketones. We further demonstrated that the reaction can be conducted in a conventional oven under neat conditions using a catalytic amount of base. The combination of the heating along with ball milling further increases the rate of the reaction but did not lead to a significant increase in yield. This method allows for the safe and easy preparation of a diverse set of aryl 2-aminothiophenes. As shown here, solvent-free methods can have a large impact in organic synthesis, especially with respect to multicomponent reactions.

\section{Acknowledgment}

We thank the National Science Foundation (CHE-0548150), and the URC at the University of Cincinnati for financial support of this research. 


\section{Conflicts of Interest}

The authors declare no conflict of interest.

\section{References}

1. Hallas, G.; Towns, A.D. Dyes derived from aminothiophenes. Part 1. Synthesis of some heterocyclic disperse dyes using the Gewald reaction. Dyes Pigm. 1996, 32, 135-149.

2. Abd-El-Aziz, A.S.; Afifi, T.H. Novel azo disperse dyes derived from aminothiophenes: Synthesis and UV-visible studies. Dyes Pigm. 2005, 70, 8-17.

3. Barnes, D.M.; Haight, A.R.; Hameury, T.; McLaughlin, M.A.; Mei, J.; Tedrow, J.S.; Dalla Riva Toma, J. New conditions for the synthesis of thiophenes via the Knoevenagel/Gewald reaction sequence. Application to the synthesis of a multitargeted kinase inhibitor. Tetrahedron 2006, 62, 11311-11319.

4. Kozikowski, A.P.; Tuckmantel, W.; Saxena, A.; Doctor, B.P. Synthesis of the thiazolone analog of the acetylcholinesterase inhibitor, huperzine A. Helv. Chim. Acta 1994, 77, 256-266.

5. Aumann, K.M.; Scammells, P.J.; White, J.M.; Schiesser, C.H. On the stability of 2-aminoselenophene-3-carboxylates: Potential dual-acting selenium-containing allosteric enhancers of A1 adenosine receptor binding. Org. Biomol. Chem. 2007, 5, 1276-1281.

6. Campaigne, E. Comprehensive Heterocyclic Chemistry; Pergamon Press: New York, NY, USA, 1984; Volume 4, pp. 863-934.

7. Gewald, K. Recent syntheses of heteroaromatic amines by cyclizations of nitriles. Lect. Heterocycl. Chem. 1982, 6, 121-138.

8. Gronowitz, S. Thiophene and Its Derivatives; Gronowitz, S., Ed.; John Wiley \& Sons: New York, NY, USA, 1985; pp. 631-799.

9. Gewald, K. Reaction of a-oxomercaptans with nitriles. Angew. Chem. 1961, 73, 114.

10. Litvinov, V.P.; Sharanin, Y.A.; Babichev, F.S. Cyclization of nitriles as synthetic route to 2- and 3-aminothiophenes. Sulfur Rep. 1986, 6, 97-135.

11. Sabnis, R.; Rangnekar, D.; Sonawane, N. 2-Aminothiophenes by the Gewald reaction. J. Heterocycl. Chem. 1999, 36, 333-345.

12. Tormyshev, V.M.; Trukhin, D.V.; Rogozhnikova, O.Y.; Mikhalina, T.V.; Troitskaya, T.I.; Flinn, A. Aryl alkyl ketones in a one-pot Gewald synthesis of 2-aminothiophenes. Synlett 2006, 2559-2564.

13. Zhang, H.; Yang, G.; Chen, J.; Chen, Z. Gewald synthesis of 2-aminothiophenes on a soluble polymer-support. J. Chem. Res. 2004, 360-361.

14. Zhang, H.; Yang, G.; Chen, J.; Chen, Z. Synthesis of thiophene derivatives on soluble polymer-support using Gewald reaction. Synthesis 2004, 3055-3059.

15. Castanedo, G.M.; Sutherlin, D.P. Synthesis of tetrasubstituted thiophenes on solid-support using the Gewald reaction. Tetrahedron Lett. 2001, 42, 7181-7184.

16. Hu, Y.; Wei, P.; Huang, H.; Han, S.-Q.; Ouyang, P.-K. Microwave-assisted Gewald synthesis of 2-aminothiophenes using functional ionic liquid as soluble support. Heterocycles 2006, 68, $375-380$. 
17. Kathiravan, M.K.; Shishoo, C.J.; Chitre, T.S.; Mahadik, K.R.; Jain, K.S. Efficient synthesis of substituted 2-amino-3-carbethoxythiophenes. Synth. Commun. 2007, 37, 4273-4279.

18. Hu, Y.; Wei, P.; Huang, H.; Han, S.-Q.; Ouyang, P.-K. Synthesis of 2-aminothiophenes on ionic liquid phase support using the Gewald reaction. Synth. Commun. 2006, 36, 1543-1548.

19. Hu, Y.; Chen, Z.-C.; Le, Z.-G.; Zheng, Q.-G. Organic reactions in ionic liquids. Gewald synthesis of 2-aminothiophenes catalyzed by ethylenediammonium diacetate. Synth. Commun. 2004, 34, 3801-3806.

20. Rajagopal, R.; Jyothi, T.M.; Daniel, T.; Srinivasan, K.V.; Rao, B.S. Calcined Mg-Al hydrotalcite as a heterogeneous base catalyst for Gewald aminothiophene synthesis. Synth. Commun. 2001, 31, 3113-3117.

21. James, S.; Adams, C.; Bolm, C.; Braga, D.; Collier, P.; Friscic, T.; Grepioni, F.; Harris, K.; Hyett, G.; Jones, W.; et al. Mechanochemistry: opportunities for new and cleaner synthesis. Chem. Soc. Rev. 2012, 41, 413-447.

22. Stolle, A.; Szuppa, T.; Leonhardt, S.E.S.; Ondruschka, B.; Leonhardt, S. Ball milling in organic synthesis: Solutions and challenges. Chem. Soc. Rev. 2011, 40, 2317-2329.

23. Wang, G.-W. Mechanochemical organic synthesis. Chem. Soc. Rev. 2013, 42, 7668-7700.

24. Mack, J.; Shumba, M. Rate enhancement of the Morita-Baylis-Hillman reaction through mechanochemistry. Green Chem. 2007, 9, 328-330.

25. Dong, Y.-W.; Wang, G.-W.; Wang, L. Solvent-free synthesis of naphthopyrans under ball-milling conditions. Tetrahedron 2008, 64, 10148-10154.

26. Concas, A.; Lai, N.; Pisu, M.; Cao, G. Modelling of comminution processes in Spex Mixer/Mill. Chem. Eng. Sci. 2006, 61, 3746-3760.

(C) 2014 by the authors; licensee MDPI, Basel, Switzerland. This article is an open access article distributed under the terms and conditions of the Creative Commons Attribution license (http://creativecommons.org/licenses/by/3.0/). 